\title{
PROPALADORA, O LA HISTORIA A PRUEBA*
}

\author{
Geneviève Fraisse
}

Centre National de la Recherche Scientifique (CNRS)

\section{PROPALAR}

Propalar es desplazarse, es tener un petate, lleno de mercancías. Propalar es no tener más que su cuerpo para transportarse, para viajar, sea porque no se tienen los medios, sea porque la finalidad del viaje hace necesaria una forma singular de recorrido. Propalar es trazar su camino. Aquí se trata de un recorrido por el pensamiento feminista. La propaladora del feminismo, figura contemporánea, practica el recorrido individual en una historia colectiva en un momento de la historia, finales del XX, principios del XXI, en el que ésta se está escribiendo.

Pero ¿por qué? Porque en el pensamiento instituido no hay lugar fijo, punto de partida asegurado, ni espacio ya dado, al objeto sexo/género. Esa cuestión, emparejada con la de la igualdad entre los sexos, con la de la emancipación femenina, no es un objeto legítimo en la tradición filosófica (al igual que hasta recientemente no lo era en otras disciplinas). Hace falta, en consecuencia, aceptar partir de lo empírico para construir una epistemología. "El feminismo, piensa", he escrito para presentar textos periodísticos, y la caja de herramientas elegida no sabría ser ortodoxa. Lo que hoy aquí se relata da testimonio de una necesidad comprendida a posteriori, no de una elección elaborada al iniciar el viaje.

\footnotetext{
* Traducción de Lourdes Mendez
} 
Ser propaladora es haber aceptado la necesidad de la libertad, la de construir a partir de trozos desparramados del saber; es por lo tanto comprometerse con una estrategia de pensamiento que se construye sobre la marcha. A raíz de lo cual dotar de inteligibilidad al pensamiento feminista es, claramente, una ambición teórica.

Ciertamente no hay lugar atribuido por la tradición, no hay filosofema sexo/género. Pero, ¿por qué el desplazamiento, el movimiento, compensaría esa ausencia de puerto de amarre? Simplemente porque sólo la historia, la historia del pasado y la que está en proceso, puede dar materia propicia a la conceptualización. Se puede incluso avanzar que la actualidad, la del feminismo desde los años setenta, es el crisol, la materia, que por fin permite crear un espacio de inteligibilidad. Así, de golpe, esa materia ha convocado el conocimiento genealógico de la emancipación de las mujeres dado por la Historia moderna y contemporánea, por la era democrática.

Hasta los años 2000 yo me veía como un soldado de infantería, no con la idea de llevar a cabo una guerra sino por estar convencida de que la pertenencia a un grupo, a un colectivo, el de las feministas, hacía de mí una soldado entre otras, una soldado preocupada por avanzar dentro de un conjunto. Luego preferí la imagen de la propaladora. La figura de la propaladora, como la del soldado de infantería, designa una situación horizontal y sin vista aérea. No habrá control. La diferencia, entonces, en el paso de una figura a la otra, tiene que ver con la distinción entre ser un ejemplar, o ser una singularidad. En un doble compromiso teórico y práctico, la singularidad ha prevalecido, motivada por una ambición personal, la de fabricar inteligibilidad, unida a la comprensión de un compromiso específico. Mi hipótesis filosófica es la de la historicidad, la de una temporalidad subversiva que se desvía del esquema de la deconstrucción social enfrentándose a la ineluctable cantinela del eso es así "desde siempre" asignada a las relaciones entre los sexos...

Entre lo que en su petate es portado y aportado por la propaladora se distinguirán tres objetos: noticias, mercancías y una linterna mágica. Cojamos un ejemplo, el de un texto publicado en el blog LibéRation de filosofía 1, en octubre 2015: se trata de Olympe de Gouges y del busto cuya inauguración en la Asamblea Nacional se pospuso (isine die?). Así la noticia, la información, es el seguimiento de un culebrón que dura desde hace más de veinte años, el del reconocimiento por parte de la nación del rol de esta mujer durante la Revolución francesa, de su dimensión histórica de actora política. Encabezando la lista del sondeo electrónico de personas propuestas para entrar en el Panteón en 2014, alejada por la presidencia de la República del lugar de los "grandes hombres", es elegida por la Asamblea Nacional para tener un busto, al lado del de Jean Jaurés. Pero el busto no está preparado para el día previsto. Esa es la noticia, la actualidad de octubre 2015. La mercancía, es decir el análisis de la dificultad para reconocerla como una "gran mujer", honra de la patria, permite distinguir entre la heroína política y la representante del 
pueblo; subraya la pertinencia de darle un lugar en la casa de los electos de la nación puesto que Olympe de Gouges pensaba que una mujer podía subir a la tribuna (y no sólo al patíbulo).

¿Y la linterna mágica? Ésta ilumina su relación con el pueblo a través de su alegato a favor de la igualdad de los sexos y de su estatura de mujer pública, iluminación aportada por una carta recientemente adquirida por la Asamblea Nacional, carta que precede unos días al 14 de julio de 1789 y en la que escribe que hay que acordarse del pueblo. Así, la actualidad es una ocasión de reflexión y de construcción de puntos de referencia a partir de la genealogía histórica.

Por eso no hay una posición de vista aérea teórica con antelación a la investigación, ni control de un objeto que ya está ahí. En cambio, podría haber una pretensión filosófica, la de inscribir el pensamiento feminista en un marco universal, la de trabajar para sacarlo de su supuesta particularidad. O de sobre cómo la historia de Olympe de Gouges, incesantemente revisitada, se inscribe en esta "democracia exclusiva" que dice a un tiempo la inscripción y la exclusión de categorías sociales producidas por la propia dinámica de la Revolución francesa.

\section{LA HISTORIA A PRUEBA}

La Historia es, por lo tanto, doblemente convocada: es un poner a prueba, lugar de compromiso necesario, o ineludible, y una prueba, un saber que, reconstituido o construido, organiza la inteligibilidad.

\section{EL COMPROMISO}

Un día se analizará "la suerte de una generación”, la que tenía 20 años en 1968, estudiaba en la Sorbona, estaba tanto en la calle con el MLF ${ }^{1}$ y otras urgencias, como en la biblioteca para devorar los archivos feministas. Mi generación. Esos años setenta es el encuentro con Jacques Rancière y la fundación de la revista Les Révoltes logiques en 1975, el cruce con Les Temps Modernes y sus fundadores ${ }^{2}$. Entrar al CNRS ${ }^{3}$ en 1983 fue una herramienta para seguir trabajando. Mi proyecto se titulaba "los fundamentos filosóficos del discurso feminista”.

El compromiso se expresa en dos experiencias intelectuales que todavía hoy actúan, por una parte, la experiencia de la contradicción, por otra, la de la relación teoría-práctica. La contradicción entre luchas solidarias fue una evidencia estructural. No obstante, la emancipación de las mujeres siempre coge a contrapelo a la de los trabajadores y a la

1. MLF (Mouvement de Libération des Femmes). Movimiento de Liberación de las Mujeres. (NdT).

2. Jean Paul Sartre y Simone de Beauvoir fundaron en 1945 la revista a la que alude G. Fraisse. (NdT).

3. CNRS (Centre National de la Recherche Scientifique). Centro Nacional de Investigación Científica. $(\mathrm{NdT})$. 
de las razas, no porque se opongan entre sí sino porque, en su contigüidad política, hay necesariamente una tensión en las elecciones estratégicas. La jerarquía de las luchas es intrínseca a la realidad política. "Las mujeres" eran, en especial en lenguaje marxista, una contradicción "secundaria". Paréntesis muy contemporáneo: a partir de ahora el término "interseccionalidad" gira en torno a una doble exigencia, científica y política, epistemológica y militante. Está seguramente la idea de sobrepasar la contradicción. Sin embargo no se esquivará la dificultad ya que las tensiones estratégicas no dejan de tener consecuencias teóricas. Por mi parte, he propuesto hablar de "contigüidad".

La segunda experiencia fue la de interpelarnos mutuamente sobre la posible relación entre teoría y práctica. El altuserianismo, y luego el maoísmo, suscitaban la cuestión del lazo entre los dos términos. Pero, más aún, pensábamos en la "práctica teórica", especie de aleación con múltiples facetas, la de la acción radical, la de la subversión intelectual.

Así el compromiso era una causa y no una consecuencia del pensamiento, una base en la que colocarse para reflexionar. La implicación política iba pareja a la curiosidad intelectual. De ahí, como una evidencia, la insuficiencia de reivindicar su campo, o de dar su opinión, puesto que no se trataba sólo de defender una posición sino de enunciar las condiciones de posibilidad. Desde ese punto de vista un ejemplo claro puede ser la comparación entre Jean Paul Sartre y Simone de Beauvoir, intelectuales y escritores a un tiempo. Básicamente, dice Sartre en Plaidoyer pour les intellectuels, el intelectual puede aparecer como quien se inmiscuye en lo que no son sus asuntos; mientras que Beauvoir, salta a la vista, en sus libros Le deuxième sexe y Viellesse se inmiscuye en lo que la atañe. En ese sentido el "privilegio" de Simone de Beauvoir, término que pongo en evidencia y en epígrafe de su escritura, viene de esa misma escritura y la frecuencia de esa palabra bajo su pluma da una versión multiforme del lugar que ella se da a sí misma, a lo largo de su vida, en un compromiso tanto práctico como teórico. El privilegio no es lo que obstaculiza su trabajo y su compromiso, sino lo que se analiza como un dato para estar lo más cerca de sus competencias. Por eso la intelectual no es sólo una eventual representante de su época, en este caso de la renovación del feminismo en la segunda mitad del siglo XX, es más simplemente, y con mayor fuerza, representativa, ejemplar.

Poco después del recorrido de Simone de Beauvoir, implicada en sus textos por su situación de mujer y osando asumirlo, el paso al intelectual específico propuesto por Michel Foucault sobreviene como una simple concatenación. Partir de lo específico, es decir de su saber acumulado, es aquello a partir de lo cual una palabra puede justificarse $y$ ofrecer un contenido apropiado al compromiso. Hoy puede suceder que al intelectual específico se le perciba como a un experto que solo vale para emitir conocimientos. Se trata de un increíble contrasentido que se explica con demasiada facilidad por cómo es nuestro siglo XXI. Subrayemos por tanto que el intelectual específico no es un experto, sino un sabio que extrae su fuerza política de lo que sabe, y no de lo que no sabe. 
En la tensión entre la posición (o la postura) y el saber, la intelectual feminista elige precisamente pensar el "qué" y no demorarse sobre el "quien", pensar el problema, y no la identidad. Volveré sobre esto.

En este instante puede intentar comprenderse cómo se inscribe en este linaje izquierdista el "saber situado", hoy referente en materia de inscripción social y política de quienes investigan. Si de lo que se trata es de analizar lo "dado en el punto de partida" de quien investiga (como el del intelectual comprometido en la polis), dado que debe saber quien lee la investigación, podemos preguntarnos en qué haría eso progresar el "desde dónde hablas" de los setenta. ¿En que habría menos interpelaciones desconfiadas y mayor preocupación de epistemología política?

\section{EL PONER A PRUEBA, LA PRUEBA}

El poner a prueba es simplemente político. Hay que tomar acta de las contradicciones políticas ya evocadas, contradicciones estratégicas en función del rol primario o secundario atribuido a los grupos dominados. Y luego ir más allá y entrar en el tema del feminismo, por ejemplo, formulando problemas. Formular problemas es alejarse de la opinión, de esa opinión a la que querría reducirse el compromiso, para ir hacia una expresión filosófica de una cuestión política, la de la igualdad de los sexos.

Rápidamente, algunos ejemplos de la puesta a prueba de la Historia que se está escribiendo:

1) El servicio doméstico: no el trabajo doméstico, no las trabajadoras domésticas, sino la ecuación servicio/igualdad. Caso concreto de la jerarquía de las mujeres dentro de la clase mujeres: las feministas de 1900 ya habían identificado la dificultad. En lo que me concierne, a finales de los setenta se trataba de establecer el lazo entre el trabajo doméstico gratuito efectuado por todas las mujeres, la llamada al feminismo lucha de clases (las trabajadoras primero), y el hecho intangible del millón de mujeres pagadas por ese trabajo doméstico. La noción, el concepto de "servicio", permite nombrar una cuestión, la del lugar del servicio en la democracia.

2) La democracia exclusiva: o el cómo la ruptura revolucionaria permite e impide el pensamiento de la igualdad de los sexos. Mediante mecanismos propios a un sistema democrático moderno se reconstruye un pensamiento de la exclusión de las mujeres adaptado al nuevo régimen político, en especial gracias a la oposición entre la excepción y la regla, las costumbres y las leyes, la razón y el sexo. Y cuando se confrontan democracia y república se ven reaparecer los dos gobiernos, el civil y el doméstico, para establecer un reparto republicano entre familia y polis, una distinción entre las dos "mitades de la república", dice Rousseau. Separación clásica de los gobiernos mientras que la modernidad introduce el concepto de representación. Así se diferencia el movimiento por la paridad, donde apunté la distinción entre gobernar y representar, entre ser nombrada y ser elegida, dos formas totalmente específicas de entrar en política. 
3) El consentimiento: en los años noventa se debatía sin fin sobre la veracidad del consentimiento de una joven que decide llevar velo, o de la de una prostituta que asume su oficio. Se puede estar a favor de llevar el velo y en contra de la prostitución; o a la inversa. Eso depende de la opinión militante. Uniendo las dos cuestiones desde el punto de vista del acto de consentir, cuya complejidad ha sido establecida por los tres siglos de modernidad del contrato, se puede plantear la cuestión del consentimiento no como un simple argumento individual e individualista, sino más bien como un argumento político inventando el mundo de mañana. De este modo el consentimiento político ofrece otro marco teórico que el de la filosofía neoliberal.

Porque la propalación, recorriendo la Historia, es un poner a prueba conceptual. Y, con una alegre ironía y en beneficio de la propaladora se podría dar la vuelta a una frase de Diderot: escribe en Sur les femmes que mientras que los hombres "leen en los libros", las mujeres leen "en el gran libro del mundo". La propaladora lee en el gran libro del mundo: sí, y por ahí puede identificarse el pensamiento feminista. Así, está el poner a prueba, la dificultad, la complejidad de una cuestión, y luego está la prueba, lo que prueba, lo que puede verificarse. Una vez más, algunos ejemplos: 1) ¿debe decirse "conciliación" de la vida privada y profesional, o "articulación", como propongo en 1997-98 cuando soy delegada interministerial encargada de los derechos de las mujeres? Si uso la palabra "articulación" estoy en la construcción de una evolución social, búsqueda activa de emancipación en vistas a una compatibilidad entre trabajo y familia; si uso la palabra "conciliación" levanto acta de una dificultad crónica, propia de la vida de las mujeres, fracaso renovado más que desafío de invención social. 2) La paridad: ¿hay que debatir realmente sobre la diferencia de los sexos como fundamento de lo político o, al contrario, como inherente a lo universal? A finales de los noventa el debate era intenso. $\mathrm{O}$, esa fue mi propuesta, ¿hace falta observar el impacto, la dinámica de igualdad y emancipación, desencadenada por el movimiento a favor de la paridad? Entonces propuse invertir la fórmula kantiana y decir que la paridad es "verdad en la práctica y falsa en la teoría". Lo que afirmo es que el debate filosófico versa sobre la pertinencia del movimiento político y no sobre su eventual buen fundamento teórico. E incluso todavía más prosaico es señalar que "sólo el número prueba" para demostrar la desigualdad del reparto de poder entre los sexos. Materialidad matemática que tiene la fuerza de una demostración; verdad en la práctica.

Demostrar: es así como hay que comprender mi paso a la vida política. Fue un "servicio político", un servicio como el de alistarse, siete años de vida dedicada a un mundo que nunca me había destinado a conocer. La prueba: aprovechar ese tiempo dado a la vida gubernamental, ser delegada interministerial, y a la vida de la representación política, ser elegida al parlamento europeo, para someter a prueba la relación entre teoría y práctica; pero no tanto el paso de una a otra, de la práctica a la teoría, del MLF a las investigaciones 
en biblioteca y, a la inversa, de la teoría a la práctica, para la intelectual requerida para devenir una mujer política extraída de la sociedad civil. No, el paso a la práctica es ante todo el de la verificación, verificación por el lenguaje sometido a lo real.

\section{EL PETATE}

Hay la mercancía transportada, y hay la oferta de imágenes que puede ofrecer la linterna mágica.

La mercancía es, evidentemente, el saber, un saber acumulado gracias al trabajo de genealogista de la democracia. Se precisará que el saber no es la ciencia. Elementos de comprensión, pero no teoría. Para construir los problemas, para identificar las nociones susceptibles de sintetizar debates o de transformarlos en objeto filosófico, sólo los textos, documentos, rastros de estos tres últimos siglos dan una materia. Luego esa materia se ordena en torno a la cuestión planteada. Así, en el petate, sólo hay objetos propios a la igualdad de los sexos y a la libertad de las mujeres, relacionados con cuestiones políticas, y ligados y religados al mundo común, universal.

En este lugar del testimonio se impone una cuestión importante. El pensamiento feminista siempre ha estado animado por un debate central, el de la alternativa entre igualdad y diferencia, universalismo y diferencialismo. Voluntariamente he mantenido ese debate a distancia, e incluso dejado de lado; diciéndolo "aporético" en el vis à vis entre identidad y diferencia, calificando la expresión "diferencia de los sexos", Gechlechtdifferenz, decía Hegel, de "categoría vacía". Hoy el debate usa otros términos, género y queer, permitiendo el uno, el género, naturalmente en singular porque es un concepto, pensar lo universal de los diversos sexos, y el otro la afirmación de lo múltiple de las sexualidades. El dúo "género y sexualidades", muy empleado hoy en el lenguaje académico, expresa la renovación de la problemática "universal/diferencia" y permite así interrogar el dos de la dualidad: binaria o no binaria es la formulación más actual. La cuestión está en saber si esa renovación es un desplazamiento. Si, quizás, si se subraya la recuperación de un debate de la filosofía antigua: a saber, no el uno opuesto al dos, el mismo y el otro de nuestra modernidad reciente, sino lo uno haciendo frente a lo múltiple de nuestro nuevo mundo. Valdría la pena colocar la actual discusión bajo la mirada de los fundamentos filosóficos de la antigüedad griega.

De hecho elegí, desde el inicio de la investigación, mantener me a distancia, encontrar los problemas y los conceptos que van con ellos, sin preocuparme por caracterizar el ser sexuado. Pero ¿por qué haber rechazado esta cuestión que, en el fondo, es la de la definición, quizás la de la ontología? Precisamente porque calificando la alternativa de aporía designaba de golpe una cuestión sin respuesta. Y prefería tomar atajos.

Entonces en el petate, o en la alforja de la propaladora, no está la mercancía de la definición antigua, o nueva, confortada o repensada de "sexo/género", no está la 
cuestión y la respuesta del "quien". Tal y como he intentado ilustrar aquí, lo que está es la cuestión del "qué". Ya que si desde ahora utilizo la expresión "sexuación del mundo" es para mostrar cómo cada cuestión encontrada (servicio, consentimiento, democracia, gobierno, representación, etc.,) ofrece una reflexión para la vida común, simplemente nutrida por una mirada sexuada; no sexuada como reparto de posiciones o de situaciones sino sexuada en el sentido de una iluminación más en una historia humana global.

Un ejemplo, de nuevo, el del derecho de las mujeres a disponer de sus cuerpos, gracias a una revolución científica, la contracepción (química, mecánica, y no sólo ya "natural") y el reconocimiento jurídico del aborto (legalizado o despenalizado, según los países y su historia). Leyendo y escuchando los eslogans de los años sesenta y setenta, es la formulación del habeas corpus la que se expresa con el eslogan "nuestro cuerpo nosotras mismas" precediendo al bien conocido "nuestro cuerpo nos pertenece". La recuperación del habeas corpus (Inglaterra 1679) no es anodina ya que sitúa ese derecho a decidir su fecundidad ante la mirada de esa conquista civil, situada antes de los derechos del hombre enunciados a finales del XVIII. Esta referencia nos invita a reflejar la historicidad que está en juego. Sea ese derecho de las mujeres a disponer se sus cuerpos aparece como un contratiempo en ese siglo XX que ve el triunfo del biopoder, de la manipulación de los derechos del hombre. Sea ese derecho permite desvelar un impensado de nuestra modernidad, el hecho que el cuerpo de las mujeres, antes incluso de toda civilidad y ciudadanía, es un lugar de poder masculino, por tanto de desposesión para el sexo femenino. La noción de habeas corpus se invita por tanto como a contrapelo en la controversia contemporánea sobre los "derechos del hombre". El derecho a disponer de su cuerpo, para las mujeres, ¿estaría en desajuste y en tensión, con la puesta en perspectiva polémica de los derechos del hombre en el siglo XX? ¿Una especie de contratiempo político y filosófico?

En consecuencia se entrevé el sentido de mi propuesta, la de "sexuar" nuestra mirada en lugar de dejarla, sea en el neutro de lo implícito, de lo invisible, sea en la reducción a lo particular, a lo específico. La "sexuación" propone un universal enriquecido de esa perspectiva esencial.

$\mathrm{Y}$ es entonces cuando la linterna mágica contribuye a iluminar una historia sexuada. La luz, o el haz de luz, es lo que nombro "el operador igualdad". Ese operador es un operador de pensamiento, en el sentido en el que el principio de igualdad, inherente a la era democrática, es indispensable para analizar lo contemporáneo. ¿Puede leerse la genealogía de la democracia sin encontrar la cuestión de la igualdad de los sexos? Algunos analistas lo piensan, y "evitan" esa cuestión etiquetada de secundaria. Por mi parte, tener ese principio de lectura de los textos ilumina, en vez de oscurecer, la comprensión. Aquellos, o aquellas, que se oponen a esa lectura mezclan de buen grado el principio de igualdad con las palabras de justicia, o de equidad; y eso enturbia la 
mirada sobre los dos últimos siglos. Más aún, el compromiso para leer la tensión entre democracia y república, o para reconocer la emancipación de las mujeres a partir de un principio político, la igualdad, permite escapar a aquello a lo que se querría reducir al feminismo: al militantismo, al humor, a la ideología vista como discurso fantasmática, en resumen, el no pensamiento.

A partir de ahí se entenderá que el principio de libertad, igualmente importante desde el punto de vista de la filosofía política, no tiene la misma capacidad para servir como operador: las controversias sobre la buena o mala libertad para las mujeres son de lleno lo que está en juego en múltiples polémicas que fragilizan su fuerza epistemológica estructurante; pero no su importancia política.

Entonces, se aprovechará para distinguir lo ontológico de lo político. Lo ontológico dice la aporía de lo idéntico y de lo diferente mientras que lo político, apoyándose sobre la igualdad y la libertad, dirige a lo ontológico cuestiones precisas: igualdad de razón, por lo tanto ciudadanía, la educación de un lado, y libertad del cuerpo, por lo tanto propiedad de sí y rechazo de la violencia del otro. Lo ontológico y lo político se cruzan, pero no se superponen.

Evidentemente, habría que tomar aquí el tiempo de la demostración, del caso práctico. Pero sepamos admitir que, al usar el operador igualdad, se aleja todo debate sobre el contenido de lo masculino y lo femenino. Digamos incluso que nos dispensamos de él. Se evita así la confusión de las definiciones en beneficio de una reflexión sobre el funcionamiento social e histórico de la sexuación.

\section{EL PASO A LO UNIVERSAL}

Gracias a ese haz de luz producido por el operador igualdad, se leen los autores de otro modo y sobre todo se amplía la perspectiva. Ejemplos rápidos en torno al derecho al divorcio impensable, se sabe, en la emancipación de las mujeres: se comprende con facilidad que el vizconde de Bonald escriba un libro contra el divorcio a principios del XIX, y obtenga su prohibición en 1816 (cuando había sido autorizado en 1792). Se sabe que la libertad de las mujeres es el fermento de su autonomía por venir, e induce consecuentemente un pensamiento de la igualdad de los sexos. Una mujer divorciada es una ciudadana en potencia. Más interesante es considerar la profundidad que de Bonald concede a esa polémica postrevolucionaria: el divorcio amenaza al Estado, escribe, el divorcio remodela la sociedad en profundidad. De una particularidad de la vida privada, hace una cuestión eje de la organización social. También se seguirá con interés la polémica sobre el consentimiento mutuo que suscita la ley restableciendo el divorcio (por falta) en 1884, en especial en Émile Durkheim. Él también se inquieta y argumenta para alejar una mutualidad de consentimientos entre los sexos (sin embargo ya presente en la lay 
revolucionaria). La amenaza no pesa sobre el Estado, como lo pensaba su predecesor, sino sobre la estructura de las relaciones sociales que no hay que fragilizar, ver, poner en peligro.

No carece de interés señalar que son los adversarios de la igualdad de los sexos los que mejor expresan lo que esa igualdad tiene como significación global, y no categorial. Quiero subrayar aquí ese paso, tan a menudo descuidado, a lo universal. Ya que si se presta atención a él, se gana pertinencia. Por ejemplo, cuando para comprender el día después de la Revolución francesa fabrico la expresión "democracia exclusiva", lo hago para distinguirla de la "democracia excluyente" de la antigüedad griega, para designar la tensión entre el enunciado de la igualdad de los sexos y la imposibilidad de aceptarlo en sus consecuencias. Por su capacidad formal, esa fórmula se exporta hacia otras lecturas que la de la exclusión de las mujeres. Esa capacidad de diseminación debe apreciarse.

Pero el paso a lo universal también concierne al pensamiento de la emancipación. Sea la alteración que conlleva la apropiación por parte de las mujeres de su desnudez, de la desnudez en general. Tras haber sido durante tantos siglos colocadas en una desnudez ofrecida a la mirada, en especial si se piensa en la historia del arte, las mujeres de finales del XIX recuperan esa desnudez, tanto reivindicando el poder de copiar el desnudo como representándose desnudas a sí mismas. Más aún, un siglo más tarde, la desnudez deviene política, activismo que hay que saber más expandido en el mundo que simplemente el de FEMEN. El momento de ruptura histórica puede relacionarse con Nietzsche cuando pone en condicional la relación entre mujer y verdad. Entonces se abandona la alegoría de la verdad representada por una mujer, en beneficio del sujeto que desregula las antiguas relaciones. Así, es desde el punto de vista de lo universal, entendido como la tradición clásica, desde el que la sexuación interviene como lectura a un tiempo filosófica y política.

Todos los ejemplos evocados en este texto remiten a una selección de algunas de mis obras citadas en la bibliografía que lo acompaña. En cuanto al compromiso que me acompaña en esta propalación, se encuentra por todos lados. Está en el objeto de investigación, el pensamiento feminista; en el método, volver a una epistemología política; en la ambición filosófica, demostrar la historicidad de los sexos, mostrar que los sexos hacen historia, lo que ahora llamo la sexuación del mundo. El compromiso va acompañado de la necesidad de desplazarse, de seguir un recorrido ligado a la historia que está en trance de hacerse, de no instalarse en un lugar; de volver a irse, siempre. 


\section{BIBLIOGRAFÍA}

__ Fraisse, Geneviève (1979) Service ou servitude, essai sur les femmes toutes mains __ (1989) Muse de la raison. La démocratie exclusive et la différence des sexes. Aix-enProvence: Alinea

__ (1991) Musa de la razón. Madrid: Cátedra Feminismos

_ (2000) Les deux gouvernements: la famille et la cité. Paris: Gallimard.

__ (2007) Du consentement. Paris: Seuil.

_ (2008) Le privilège de Simone de Beauvoir. Arles: Actes du Sud.

_ (2009) El privilegio de Simone de Beauvoir. Buenos Aires: Leviatan.

__ (2010) A côté du genre, sexe, et philosophie de l'égalité, Bord de l' eau.

_ (2011) Del Consentimiento. Santiago de Chile: Editorial Palinodia.

__ (2012) Del Consentimiento. México DF: UNAM-Colmex.

_ (2012) La fabrique du féminisme. Congé sur Orne: Le. passager clandestin

__ (2014) Les excès du genre, concept, image, nudité. éditions lignes.

_ (2016) La sexuation du monde. Réflexions sur l'émancipation. Paris: Presses de la Fondation Nationale des Sciences Politiques. 